\title{
Efficient and Sustained Photoelectrochemical Water Oxidation by Cobalt Oxide/Silicon Photoanodes with Nanotextured Interfaces
}

\author{
Jinhui Yang, ${ }^{\dagger, \ddagger}$ Karl Walczak, ${ }^{\dagger, \dagger}$ Eitan Anzenberg, ${ }^{\dagger, \dagger}$ Francesca M. Toma, ${ }^{\dagger, \text { Il }}$ Guangbi Yuan, ${ }^{\S}$
} Jeffrey Beeman, ${ }^{\dagger, \dagger}$ Adam Schwartzberg, ${ }^{\|}$Yongjing Lin, ${ }^{\dagger, \downarrow, \perp}$ Mark Hettick, ${ }^{\dagger, t, \perp}$ Ali Javey, ${ }^{\dagger, \perp}$ Joel W. Ager, ${ }^{\dagger, \downarrow}$ Junko Yano, ${ }^{\dagger, \S}$ Heinz Frei, ${ }^{\dagger, \S}$ and Ian D. Sharp ${ }^{* \dagger, \S}$

${ }^{\dagger}$ Joint Center for Artificial Photosynthesis (JCAP), Lawrence Berkeley National Laboratory, Berkeley, California 94720, United States

${ }^{\ddagger}$ Material Sciences Division, ${ }^{\text {II } C h e m i c a l ~ S c i e n c e s ~ D i v i s i o n, ~}{ }^{\S}$ Physical Biosciences Division, and "Molecular Foundry, Lawrence Berkeley National Laboratory, Berkeley, California 94720, United States

${ }^{\perp}$ Electrical Engineering and Computer Sciences, University of California, Berkeley, California 94720, United States

\section{Supporting Information}

ABSTRACT: Plasma-enhanced atomic layer deposition of cobalt oxide onto nanotextured $\mathrm{p}^{+} \mathrm{n}-\mathrm{Si}$ devices enables efficient photoelectrochemical water oxidation and effective protection of $\mathrm{Si}$ from corrosion at high $\mathrm{pH}(\mathrm{pH} 13.6)$. A photocurrent density of $17 \mathrm{~mA} / \mathrm{cm}^{2}$ at $1.23 \mathrm{~V}$ vs RHE, saturation current density of $30 \mathrm{~mA} / \mathrm{cm}^{2}$, and photovoltage greater than $600 \mathrm{mV}$ were achieved under simulated solar illumination. Sustained photoelectrochemical water oxidation was observed with no detectable degradation after $24 \mathrm{~h}$. Enhanced performance of the nanotextured structure, compared to planar $\mathrm{Si}$, is attributed to a reduced silicon oxide thickness that provides more intimate interfacial contact between the light absorber and catalyst. This work highlights a general approach to improve the performance and stability of $\mathrm{Si}$ photoelectrodes by engineering the catalyst/semiconductor interface.

A rtificial photosynthesis, by photoelectrochemical splitting of water into $\mathrm{H}_{2}$ and $\mathrm{O}_{2}$, is a promising approach to renewable energy conversion. ${ }^{1}$ Critical challenges toward the realization of scalable devices include the availability of suitable semiconductors for capturing the solar spectrum, efficient coupling of catalysts with semiconductors, and stability under aqueous conditions. ${ }^{2}$ Furthermore, avoiding explosive product mixtures and reducing efficiency losses due to gas crossover necessitate incorporation of membranes in current integrated systems. $^{2 b, 3}$ In the absence of recirculation, this imposes a requirement for operation under extreme $\mathrm{pH}$ conditions in order to eliminate $\mathrm{pH}$ gradients. ${ }^{3}$ Given the scarcity of acid-stable oxygen evolution reaction (OER) catalysts, ${ }^{4}$ the development of efficient and stable photoanodes that operate in alkaline conditions is vital to achieve an efficient solar-to-fuel system.

Silicon is an attractive semiconductor for solar fuel generation since it absorbs a significant fraction of the solar spectrum, is earth-abundant, and is widely used in photovoltaic applications. ${ }^{5}$ However, the realization of silicon based solar-to-fuel devices is challenging due to the intrinsic instability of this material under aqueous conditions, particularly at high $\mathrm{pH}$. In recent years, strategies for stabilizing photoanodes against corrosion and photocorrosion have been widely explored. ${ }^{1 \mathrm{~d}, 6}$ General approaches involve introducing thin corrosion protection layers that allow interfacial charge transfer of photogenerated minority carriers while physically protecting the light-absorbers. For example, np-Si devices have been passivated with transparent conductive oxides (TCOs) and can function well in near-neutral $\mathrm{pH}$ conditions when effectively interfaced with an OER catalyst (Co-Pi). ${ }^{6 c, d}$ In an alternative approach, Chen et al. showed effective protection of $\mathrm{n}-\mathrm{Si}$ by atomic layer deposition (ALD) of a $2 \mathrm{~nm}$ thick layer of $\mathrm{TiO}_{2}$, followed by e-beam evaporation of $\mathrm{Ir}$ as the OER catalyst. ${ }^{6 e}$ Water oxidation on these protected photoanodes was sustained for $>8 \mathrm{~h}$ under various $\mathrm{pH}$ conditions, including $1 \mathrm{M} \mathrm{NaOH}$, whereas analogous $\mathrm{Si}$ photanodes without $\mathrm{TiO}_{2}$ quickly failed. While incorporation of interfacial corrosion protection layers significantly improves stability by physically separating the photoanode from the electrolyte, such layers can introduce series resistance and recombination losses. ${ }^{6 e}$ To overcome these limitations, attempts have been made to utilize the OER catalyst itself for protection of Si photoanodes. $\mathrm{MnO}_{x}$ was shown to improve the stability of $\mathrm{n}-\mathrm{Si}$ in $1 \mathrm{M} \mathrm{KOH}^{6 \mathrm{~b}}$ However, corrosion in this harsh alkaline environment limited the operation time to $30 \mathrm{~min}$. Very recently, e-beam evaporation of a thin $\mathrm{Ni}$ film on $\mathrm{n}$-Si was used to simultaneously act as both the catalyst and protection layer; longterm stability was shown in the presence of a $\mathrm{LiBi}-\mathrm{KBi}$ electrolyte at intermediate $\mathrm{pH}$, and up to $24 \mathrm{~h}$ stability was achieved in $1 \mathrm{M}$ $\mathrm{KOH}$ under 2.2 sun illumination. ${ }^{\mathrm{ld}}$ This approach requires precise control of ultrathin layers to achieve appreciable photovoltages. In the present work, ${ }^{7}$ we show that direct deposition of cobalt oxide $\left(\mathrm{CoO}_{x}\right)$ by plasma-enhanced ALD on nanotextured $\mathrm{p}^{+} \mathrm{n}-\mathrm{Si}$ buried junction devices enables effective protection of Si for at least $24 \mathrm{~h}$ at high $\mathrm{pH}(1 \mathrm{M} \mathrm{NaOH}, \mathrm{pH}$ $13.6)$, while retaining a high photovoltage $(610 \mathrm{mV})$ under simulated 1 sun irradiation.

Figure 1a shows a schematic illustration of the photoanode preparation processes. First, n-Si (100) wafers were doped with boron using two different methods: drive-in diffusion and ion implantation, followed by etching in buffered HF (see SI). Next, nanotexturing of Si was achieved via Ar plasma sputtering under

Received: February 12, 2014

Published: April 10, 2014 


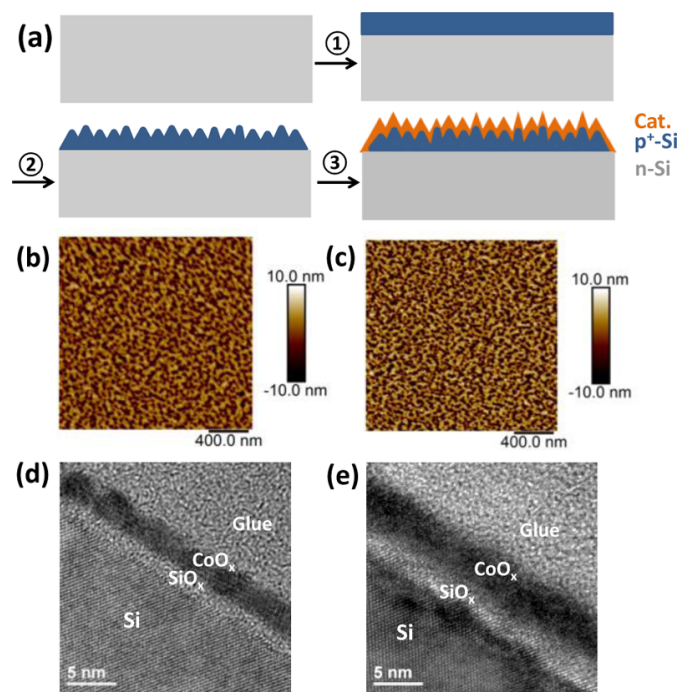

Figure 1. (a) Schematic description of the preparation of nanotextured $\mathrm{CoO}_{x} / \mathrm{p}^{+} \mathrm{n}-\mathrm{Si}$ device: (1) formation of $\mathrm{p}^{+} \mathrm{n}-\mathrm{Si}$ by diffusion or implantation of boron into (100) $\mathrm{n}-\mathrm{Si}$; (2) nanotexturing by $\mathrm{Ar}$ sputtering under substrate bias; (3) $\mathrm{CoO}_{x}$ deposition by ALD. AFM images of the corresponding (b) nanotextured $\mathrm{p}^{+} \mathrm{n}-\mathrm{Si}$ and (c) nanotextured $\mathrm{CoO}_{x} / \mathrm{p}^{+} \mathrm{n}$-Si reveal $\mathrm{rms}$ roughness values of 3.0 and 4.2 $\mathrm{nm}$, respectively. Cross section TEM images of planar (d) and nanotextured (e) structures after $\mathrm{CoO}_{x}$ deposition.

an applied substrate bias, a process that did not impact the open circuit voltage (vide infra). The effect of substrate bias sputtering on the morphology of the $\mathrm{p}^{+} \mathrm{n}$-Si surface was studied by atomic force microscopy (AFM) (Figures $1 \mathrm{~b}$ and S1a). After Ar sputtering, the root-mean-square (rms) surface roughness increased from 1.3 to $3.0 \mathrm{~nm}$ (Figures S1a and 1c). Finally, $\mathrm{CoO}_{x}$ was deposited on top of the nanotextured surface by ALD, a process that is uniquely suited for conformal deposition of overlayers on nanostructures due to its self-limiting nature and precise thickness control ${ }^{8}$ and has been shown to enhance the stability of metal oxide photoanodes. ${ }^{9}$ For comparative studies, $\mathrm{CoO}_{x}$ ALD was also performed on planar $\mathrm{p}^{+} \mathrm{n}$-Si surfaces, as described throughout the text. AFM analysis following catalyst deposition (Figure 1d) reveals a roughness value of $4.2 \mathrm{~nm}$ for $\mathrm{CoO}_{x} / \mathrm{p}^{+} \mathrm{n}$-Si with nanotextured interfaces. The increase of surface roughness is consistent with previous reports ${ }^{8}$ and is also similar on planar surfaces (increasing from 1.3 to $2.9 \mathrm{~nm}$, Figure $\mathrm{S} 1$ ), confirming that ALD is suitable for conformal $\mathrm{CoO}_{x}$ deposition and retention of the substrate surface texture. Cross-sectional transmission electron micrographs (TEM) (Figures 1d,e and S2) reveal the presence of interfacial silicon oxide layers on both planar and nanotextured samples. While the thickness of this layer is approximately constant for the planar substrate, it varies considerably with position on the nanotextured substrate, with a separation between $\mathrm{CoO}_{x}$ and $\mathrm{Si}$ of just a few atomic layers in some regions. Despite identical ALD conditions, $\mathrm{CoO}_{x}$ is found to be polycrystalline when deposited on planar Si but amorphous when deposited on nanotextured surfaces. While the origin of this structural difference is not currently known, it likely plays an important role in the stability of photoelectrodes under alkaline conditions, as discussed below.

The photoelectrochemical current density vs applied potential $(J-E)$ characteristics of both planar and nanotextured $\mathrm{CoO}_{x} /$ $\mathrm{p}^{+} \mathrm{n}$-Si were measured in aqueous $1 \mathrm{M} \mathrm{NaOH}(\mathrm{pH}$ 13.6) under $100 \mathrm{~mW} / \mathrm{cm}^{2}$ simulated air mass (AM) 1.5 illumination as a function of $\mathrm{CoO}_{x}$ thickness (Figure S3). Consistent with previous reports, bare $\mathrm{Si}$ without a catalyst degraded rapidly. ${ }^{1 \mathrm{~d}}$ Likewise, all devices with $<1 \mathrm{~nm} \mathrm{CoO}_{x}$ layers ( $<10$ cycles) were unstable and exhibited a poor photoresponse.

This is in stark contrast with previous measurements of nanostructured hematite photoanodes, ${ }^{10}$ which are inherently stable under alkaline conditions and displayed dramatically improved photocatalytic behavior upon ALD of submonolayer $\mathrm{CoO}_{x}$. In the present work, introduction of catalytically active surface sites is necessary but not sufficient for effective PEC; thicker $\mathrm{CoO}_{x}$ layers are required to ensure conformal coating and stabilize the surface against corrosion. For all investigated $\mathrm{CoO}_{x}$ thicknesses of $2 \mathrm{~nm}$ and above ( $\geq 30$ ALD cycles), nanotextured devices consistently exhibited a cathodic shift of the open circuit potential and higher current density relative to corresponding planar devices (Figures S3 and S4). Measurements of the incident-photon-to-current-efficiency (IPCE) and dependence of photocurrent on light intensity further confirm the improved performance of nanotextured devices (Figures S5 and S6). The PEC behavior of nanotextured substrates with 100 plasmaenhanced ALD cycles $(\sim 4-5 \mathrm{~nm})$ is characterized by a photocurrent density of $17 \mathrm{~mA} / \mathrm{cm}^{2}$ at thermodynamic OER potential (1.23 V vs RHE) and a saturation current density of 30 $\mathrm{mA} / \mathrm{cm}^{2}$ (Figure 2a). An identical ALD $\mathrm{CoO}_{x}$ film was applied to
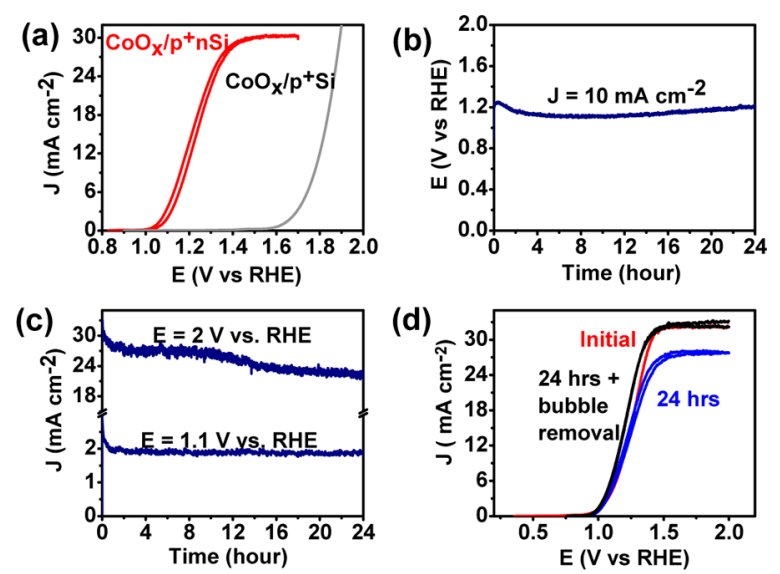

Figure 2. Photoelectrochemical behavior of nanotextured $\mathrm{CoO}_{x} / \mathrm{p}^{+} \mathrm{n}-\mathrm{Si}$ photoanode in aqueous $1.0 \mathrm{M} \mathrm{NaOH}$ under $100 \mathrm{~mW} / \mathrm{cm}^{2}$ of simulated solar illumination. (a) $J-E$ response of $\mathrm{CoO}_{x} / \mathrm{p}^{+} \mathrm{n}-\mathrm{Si}$ (red) under illumination and $\mathrm{CoO}_{x} / \mathrm{p}^{+} \mathrm{Si}$ (gray) in the dark. (b) Chronopotentiometry of nanotextured $\mathrm{CoO}_{x} / \mathrm{p}^{+} \mathrm{n}$-Si photoanode at a constant current density of $10 \mathrm{~mA} / \mathrm{cm}^{2}$. (c) Chronoamperometry of nanotextured $\mathrm{CoO}_{x} / \mathrm{p}^{+} \mathrm{n}$-Si photoanode at 2 and $1.1 \mathrm{~V}$ vs RHE. (d) $J-E$ response of nanotextured photoanodes before (red) and immediately after (blue) 24 $\mathrm{h} J-t$ stability testing. Clearing of bubbles results in complete recovery of the original $J-E$ characteristic (black).

a $\mathrm{p}^{+}$-Si wafer $(0.001-0.005 \Omega \mathrm{cm})$, which provides the baseline performance of the OER electrocatalyst. This measurement reveals that the photovoltage generated with the ion implanted $\mathrm{p}^{+} \mathrm{n}-\mathrm{Si}$ junction is $610 \mathrm{mV}$. This value is in good agreement with modern $\mathrm{p}^{+}$-emitter/n-base single crystalline $\mathrm{Si}$ photovoltaics ${ }^{11}$ and confirms that the physical nanotexturing process, together with a subsequent etching and catalyst deposition process, does not introduce deleterious near-surface recombination centers.

In order to elucidate the superior photoelectrochemical $J-E$ performance for the nanotextured $\mathrm{CoO}_{x} / \mathrm{p}^{+} \mathrm{n}-\mathrm{Si}$ device, cyclic voltammetry in the presence of a benchmark electrolyte composed of a ferri/ferrocyanide aqueous solution ${ }^{6 e}$ was performed and compared to the planar device. The peak-to- 
peak splitting was $0.25 \mathrm{~V}$ on the nanotextured sample vs $1.2 \mathrm{~V}$ on the planar sample (Figure S7). This indicates a substantial decrease of interfacial charge transfer resistance by nanotexturing the interface, which may be attributed to improved tunneling probability across regions of reduced interfacial silicon oxide thickness compared to planar systems (Figures 1e and S2).

Photoelectrode stability is an essential requirement and outstanding challenge for solar-to-fuel devices. ${ }^{2 \mathrm{a}, \mathrm{b}}$ In the present work, stability was assessed via both chronopotentiometric ( $V-$ $t$ ) and chronoamperometric $(J-t)$ operation of $\mathrm{CoO}_{x} / \mathrm{p}^{+} \mathrm{n}-\mathrm{Si}$ devices. As shown in Figure $2 \mathrm{~b}, V-t$ curves at a constant current density of $10 \mathrm{~mA} / \mathrm{cm}^{2}$, which is the approximate operational current density expected for overall solar-to-fuel conversion devices achieving $10 \%$ efficiency, ${ }^{2 a, 4}$ reveal that nanotextured $\mathrm{CoO}_{x} / \mathrm{p}^{+} \mathrm{n}$-Si devices maintain stable activity for at least $24 \mathrm{~h}$ in 1 $\mathrm{M} \mathrm{NaOH}$. $J-t$ evaluation (Figure 2c) further confirms the stability of nanotextured $\mathrm{CoO}_{x} / \mathrm{p}^{+} \mathrm{n}$-Si. Stability measurements were performed under conditions of photocurrent saturation, as well as near the open circuit potential, where the current density is particularly sensitive to degradation. Bubble accumulation during testing leads to some reduction of the photocurrent density. However, as shown in Figure 2d, clearing of bubbles results in complete recovery of the original $J-E$ characteristic, proving the stability of nanotextured $\mathrm{CoO}_{x} / \mathrm{p}^{+} \mathrm{n}-\mathrm{Si}$ over $24 \mathrm{~h}$ of continuous operation of under alkaline conditions. In contrast, the planar device is characterized by a decrease of photocurrent during the first $30 \mathrm{~min}$ of operation (Figures S8 and S9). XPS analysis reveals that there is no loss of Co from the nanotextured surface following testing for $24 \mathrm{~h}$ in $1 \mathrm{M} \mathrm{NaOH}$ (Figure S10). These results highlight the stability enhancement provided by ALD of $\mathrm{CoO}_{x}$ onto nanotextured $\mathrm{Si}$ devices.

Further insights into the stability of nanotextured photoanodes was obtained by X-ray fluorescence mapping (XRF) after chronoamperometric testing and by comparison to planar photoanodes. For XRF measurements, a portion of the electrode surface was masked to prevent electrolyte contact with the surface of the electrode. Figure $3 \mathrm{a}, \mathrm{b}$ show $\mathrm{Co} \mathrm{K} \alpha \mathrm{XRF}$ across the masked edge. In the case of the planar structure, an average of $10 \%$ loss of Co from the surface after $1 \mathrm{~h}$ stability test is observed (Figure 3a). In contrast, no loss of catalyst is observed from the nanotextured device (Figure 3b). Complementary AFM
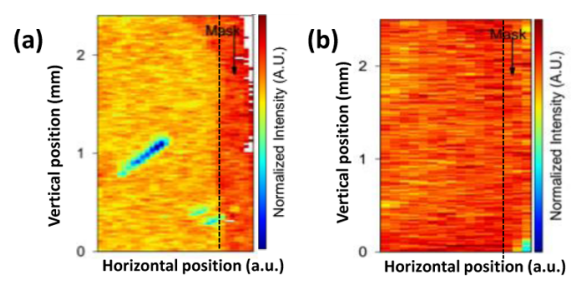

(c)

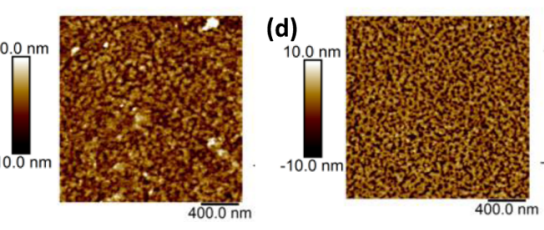

Figure 3. X-ray fluorescence (XRF) mapping with an excitation energy of $8409 \mathrm{eV}$ across the edge (vertical line) of masked and exposed areas of (a) planar and (b) nanotextured $\mathrm{CoO}_{x} / \mathrm{p}^{+} \mathrm{n}-\mathrm{Si}$ after chronoamperometric testing for $1 \mathrm{~h}$. AFM of (c) planar and (d) nanotextured $\mathrm{CoO}_{x} /$ $\mathrm{p}^{+} \mathrm{n}-\mathrm{Si}$ after photoanodic operation. The former exhibits significant corrosion, while the latter retains its initial morphology and homogeneity. measurements of electrodes after the PEC stability test provide further information about corrosion processes. While the surface morphology of the nanotextured device is unaffected by prolonged operation under OER conditions, there is substantial corrosion on the planar surfaces, as evidenced by significant morphological changes after $1 \mathrm{~h}$ (Figure 3c, d) and $24 \mathrm{~h}$ (Figure S11). Together, these XRF and AFM measurements indicate that, in the case of planar devices, etching of the underlying Si occurs under strongly alkaline conditions. In contrast, nanotexturing enhances catalyst durability on the surface, thereby stabilizing the device against corrosion.

In addition to stability under OER conditions, where anodic passivation of Si by silicon oxide could mask certain corrosion mechanisms, it is important for photoelectrodes to exhibit longterm stability under unbiased dark conditions (i.e., at night). Therefore, chemical stability of $\mathrm{CoO}_{x} / \mathrm{p}^{+} \mathrm{n}-\mathrm{Si}$ was also studied by soaking the electrodes in $1 \mathrm{M} \mathrm{NaOH}$ for $24 \mathrm{~h}$. Comparison of AFM images shows no obvious morphological changes to the nanotextured sample, while significant corrosion is observed on the planar sample (Figure S12). Furthermore, XPS analysis reveals no loss of $\mathrm{CoO}_{x}$ from the nanotextured electrode (Figure S13). Importantly, XPS also indicates that no $\mathrm{CoO}_{x}$ is lost from the surface of planar material upon unbiased soaking (Figure S13), despite under-etching of the Si substrate. These results suggest that $\mathrm{CoO}_{x}$ is chemically stable in the alkaline environment, though $\mathrm{CoO}_{x}$ is lost from planar surfaces under OER conditions (Figure 3a), likely as a consequence of simultaneous etching of $\mathrm{Si}$ and bubble formation. These results, combined with TEM, point to a possible mechanism for the enhanced stability of nanotextured compared to planar electrodes. We hypothesize that the amorphous nature of the catalyst on nanotextured surfaces is highly conformal due to the lack of crystallites, thereby preventing attack of the substrate by the alkaline solution. In contrast, polycrystalline material may be associated with higher pinhole densities in intergrain regions that permit contact of the electrolyte with the substrate. Additional experiments are underway to test this hypothesis.

Previous reports of $\mathrm{CoO}_{x} \mathrm{ALD}$ on a variety of substrates have found different chemical compositions including $\mathrm{Co}$ (II), as either $\mathrm{CoO}$ or $\mathrm{Co}(\mathrm{OH})_{2}$, and $\mathrm{Co}_{3} \mathrm{O}_{4} \cdot{ }^{8-10,12}$ In the present work, the surface composition of as-deposited films as a function of thickness was investigated using XPS (Figure S14). Following 10 ALD cycles, the Co $2 \mathrm{p}_{3 / 2}$ peak exhibits a strong satellite feature at $786.3 \mathrm{eV}$ that is indicative of a film dominated by $\mathrm{Co}$ (II). As the film thickness increases, the relative intensity of this satellite feature decreases, the primary Co $2 \mathrm{p}_{3 / 2}$ emission line shifts to lower binding energies, and a satellite feature near $789.6 \mathrm{eV}$ emerges. These changes indicate that the surfaces of thicker $\mathrm{CoO}_{x}$ films are dominated by $\mathrm{Co}_{3} \mathrm{O}_{4}$, as confirmed by comparison to reference spectra (Figure S15), as well as existing literature. $^{13}$

Since XPS is only sensitive to surface composition, X-ray absorption near-edge spectroscopy (XANES) was used for complementary analysis of the overall composition of ALD thin films. XANES data collected following 60 ALD cycles, together with $\mathrm{Co}_{3} \mathrm{O}_{4}$ and $\mathrm{Co}(\mathrm{OH})_{2}$ reference spectra, are shown in Figure $4 \mathrm{~b}$. Fitting a linear combination of the reference spectra to data from the ALD $\mathrm{CoO}_{x}$ revealed that the thin films are composed of $\sim 20 \% \mathrm{Co}$ (II) and $\sim 80 \%$ of $\mathrm{Co}_{3} \mathrm{O}_{4}$, whereas XPS indicated that the surface is dominated by $\mathrm{Co}_{3} \mathrm{O}_{4}$. These combined results indicate that the thick ALD $\mathrm{CoO}_{x}$ films are composed of $\mathrm{Co}_{3} \mathrm{O}_{4}$ with an underlying interfacial $\mathrm{Co}$ (II), most likely $\mathrm{CoO}$, considering the $\mathrm{Co}(\mathrm{Cp})_{2}$ precursor and $\mathrm{O}_{2}$ plasma used in 

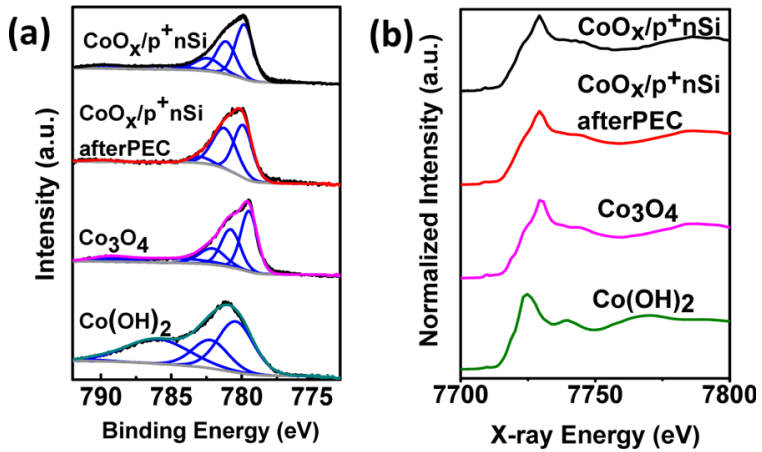

Figure 4. (a) XPS (Co 2 $\mathrm{p}_{3 / 2}$ ) and (b) XANES (Co K-edge) spectra of $\mathrm{CoO}_{x} / \mathrm{p}^{+} \mathrm{n}$-Si samples: as-deposited and after PEC stability testing for 1 $\mathrm{h}$ at an overpotential of $400 \mathrm{mV}$ in $1 \mathrm{M} \mathrm{NaOH}$ ( $\mathrm{pH} 13.6)$, as well as $\mathrm{Co}_{3} \mathrm{O}_{4}$ and $\mathrm{Co}(\mathrm{OH})_{2}$ standards.

deposition. The composition following PEC testing for 1 hour was also examined by XPS and XANES. While XANES reveals that the bulk of the film is composed of a fixed ratio of $\mathrm{Co}_{3} \mathrm{O}_{4}$ and $\mathrm{Co}(\mathrm{OH})_{2}$ (Figure 4b), XPS shows transformation of the surface to $\mathrm{CoO}(\mathrm{OH})$ (Figures 4a, S16 and S17), which is in consistent with previous reports. ${ }^{14}$ We note that the same composition behavior is observed on both planar and nanotextured Si surfaces, despite the different structures of these films.

In conclusion, we have developed a straightforward approach to dramatically improve the activity and stability of $\mathrm{Si}$ photoanodes by plasma-enhanced ALD on nanotextured Si surfaces formed via physical Ar sputtering of $\mathrm{p}^{+} \mathrm{n}-\mathrm{Si}$ devices. Photovoltages as high as $610 \mathrm{mV}$ were obtained, with stable operation for at least $24 \mathrm{~h}$ in $1 \mathrm{M} \mathrm{NaOH}$ under simulated solar illumination. Nanotexturing the interface between $\mathrm{CoO}_{x}$ and $\mathrm{Si}$ decreases interfacial charge transfer resistance by locally reducing the silicon oxide thickness and increases stability, enabling sustained operation. This work highlights an approach to stabilizing semiconductor photoelectrodes for efficient operation under the harsh conditions required for solar water splitting by engineering catalyst/semiconductor interfaces.

\section{ASSOCIATED CONTENT}

\section{S Supporting Information}

Materials, instruments, synthesis, XPS spectra, XANES data, cyclic voltammetry. This material is available free of charge via the Internet at http://pubs.acs.org.

\section{AUTHOR INFORMATION}

\section{Corresponding Author}

idsharp@lbl.gov

Notes

The authors declare no competing financial interest.

\section{ACKNOWLEDGMENTS}

This material is based upon work performed by the Joint Center for Artificial Photosynthesis, a DOE Energy Innovation Hub, supported through the Office of Science of the U.S. Department of Energy under Award Number DE-SC0004993. ALD Work were performed at the Molecular Foundry, XANES experiments were performed at the Advanced Light Source (beamline 10.3.2), and TEM work was performed at NCEM, all supported by the U.S. Department of Energy (DOE), Office of Basic Energy Sciences, Scientific User Facilities Division, under Contract No. DE-AC02-05CH11231. We gratefully acknowledge Gary F.
Moore and Alexandra Krawicz for PEC setup and cell design; Le Chen for guidance with use of the sputtering system; and Shu $\mathrm{Hu}$, Michael Lichterman, and Nate Lewis for insightful discussions.

\section{REFERENCES}

(1) (a) Lewis, N. S.; Nocera, D. G. Proc. Natl. Acad. Sci. U.S.A. 2006, 103, 15729. (b) Maeda, K.; Teramura, K.; Lu, D. L.; Takata, T.; Saito, N.; Inoue, Y.; Domen, K. Nature 2006, 440, 295. (c) Reece, S. Y.; Hamel, J. A.; Sung, K.; Jarvi, T. D.; Esswein, A. J.; Pijpers, J. J. H.; Nocera, D. G. Science 2011, 334, 645. (d) Kenney, M. J.; Gong, M.; Li, Y.; Wu, J. Z.; Feng, J.; Lanza, M.; Dai, H. Science 2013, 342, 836. (e) Youngblood, W. J.; Lee, S.-H. A.; Maeda, K.; Mallouk, T. E. Acc. Chem. Res. 2009, 42, 1966. (f) Dahl, S.; Chorkendorff, I. Nat. Mater. 2012, 11, 100.

(2) (a) Parkinson, B. Acc. Chem. Res. 1984, 17, 431. (b) McKone, J. R.; Lewis, N. S.; Gray, H. B. Chem. Mater. 2013, 26, 407. (c) Yang, J.; Wang, D.; Han, H.; Li, C. Acc. Chem. Res. 2013, 46, 1900.

(3) Modestino, M. A.; Walczak, K. A.; Berger, A.; Evans, C. M.; Haussener, S.; Koval, C.; Newman, J. S.; Ager, J. W.; Segalman, R. A. Energy Environ. Sci. 2014, 7, 297.

(4) McCrory, C. C. L.; Jung, S.; Peters, J. C.; Jaramillo, T. F. J. Am. Chem. Soc. 2013, 135, 16977.

(5) (a) Yuan, G.; Zhao, H.; Liu, X.; Hasanali, Z. S.; Zou, Y.; Levine, A.; Wang, D. Angew. Chem. In. Ed. 2009, 121, 9860. (b) Boettcher, S. W.; Spurgeon, J. M.; Putnam, M. C.; Warren, E. L.; Turner-Evans, D. B.; Kelzenberg, M. D.; Maiolo, J. R.; Atwater, H. A.; Lewis, N. S. Science 2010, 327, 185 .

(6) (a) Sun, K.; Pang, X.; Shen, S.; Qian, X.; Cheung, J. S.; Wang, D. Nano Lett. 2013, 13, 2064. (b) Strandwitz, N. C.; Comstock, D. J.; Grimm, R. L.; Nichols-Nielander, A. C.; Elam, J.; Lewis, N. S. J. Phys. Chem. C 2013, 117, 4931. (c) Cox, C. R.; Winkler, M. T.; Pijpers, J. J. H.; Buonassisi, T.; Nocera, D. G. Energy Environ. Sci. 2013, 6, 532. (d) Pijpers, J. J.; Winkler, M. T.; Surendranath, Y.; Buonassisi, T.; Nocera, D. G. Proc. Natl. Acad. Sci. U.S.A. 2011, 108, 10056. (e) Chen, Y. W.; Prange, J. D.; Dühnen, S.; Park, Y.; Gunji, M.; Chidsey, C. E.; McIntyre, P. C. Nat. Mater. 2011, 10, 539. (f) Contractor, A. Q.; Bockris, J. O. M. Electrochim. Acta 1984, 29, 1427. (g) Fan, F. R. F.; Keil, R. G.; Bard, A. J. J. Am. Chem. Soc. 1983, 105, 220. (i) Campet, G.; Puprichitkun, C.; Sun, Z. W. J. Electroanal. Chem. Interfacial Electrochem. 1989, 269, 435.

(7) This work is part of a focused approach, involving multiple JCAP projects and investigators, dedicated to the protection of otherwise unstable photoelectrodes in aqueous environments.

(8) Donders, M.; Knoops, H.; Kessels, W.; Notten, P. J. Electrochem. Soc. 2011, 158, G92.

(9) Lichterman, M. F.; Shaner, M. R.; Handler, S. G.; Brunschwig, B. S.; Gray, H. B.; Lewis, N. S.; Spurgeon, J. M. J. Phys. Chem. L 2013, 4, 4188.

(10) Riha, S. C.; Klahr, B. M.; Tyo, E. C.; Seifert, S.; Vajda, S.; Pellin, M. J.; Hamann, T. W.; Martinson, A. B. F. ACS Nano 2013, 7, 2396.

(11) Meier, D. L.; Chandrasekaran, V.; Davis, H. P.; Payne, A. M.; Xiaoyan, W.; Yelundur, V.; O’Neill, E.; Young-Woo, O.; Zimbardi, F.; Rohatgi, A. IEEE J. Photovolt. 2011, 1, 123.

(12) Diskus, M.; Nilsen, O.; Fjellvåg, H. Chem. Vap. Deposition 2011, $17,135$.

(13) (a) Biesinger, M. C.; Payne, B. P.; Grosvenor, A. P.; Lau, L. W. M.; Gerson, A. R.; Smart, R. S. C. Appl. Surf. Sci. 2011, 257, 2717. (b) Yang, J.; Liu, H.; Martens, W. N.; Frost, R. L. J. Phys. Chem. C 2009, 114, 111.

(14) Kanan, M. W.; Yano, J.; Surendranath, Y.; Dinca, M.; Yachandra, V. K.; Nocera, D. G. J. Am. Chem. Soc. 2010, 132, 13692. 